LEITERS TO THE EDITOR

If you have a burning desire to respond to a paper published in Thorax, why not make use of our "rapid response" option? Log on to our website (www.thoraxjnl.com), find the paper that interests you, and send your response via email by clicking on the "eLetters" option in the box at the top right hand corner.

Providing it isn't libellous or obscene, it will be posted within seven days. You can retrieve it by clicking on "read eletters" on our homepage.

The editors will decide as before whether to also publish it in a future paper issue.

\section{GM-CSF therapy in pulmonary alveolar proteinosis}

Treatment with granulocyte-macrophage colony stimulating factor (GM -CSF) has been shown to benefit a subset of patients with adult pulmonary alveolar proteinosis (PAP). A 47 year old woman with PAP, confirmed by lung biopsy, and severe physiological and symptomatic disturbances was not improved by repeated unilateral whole lung lavages. Six months after the last lavage we started treatment with daily subcutaneous GM-CSF in increasing doses beginning at $3 \mu \mathrm{g} / \mathrm{kg}$. When a daily dose of $6 \mu \mathrm{g} / \mathrm{kg}$ was reached a haematological response was detected and dose escalation ceased. After 4 weeks at this dose the patient began to improve. By week 11 at a dose of $6 \mu \mathrm{g} / \mathrm{kg} /$ day the treatment was stopped and after a further 3 weeks without treatment she attained maximal clinical radiological, and physiological improvement (from arterial oxygen tension $\left(\mathrm{PaO}_{2}\right) 6.1 \mathrm{kPa}$, alveolar-arterial oxygen gradient $\left((\mathrm{A}-\mathrm{a}) \mathrm{O}_{2}\right)$ $8.2 \mathrm{kPa}$, total lung capacity (TLC) $63.3 \%$, and carbon monoxide transfer factor (TLCO) $58.7 \%$ at diagnosis to $10.9 \mathrm{kPa}, 2.6 \mathrm{kPa}, 99 \%$, and $101.1 \%$, respectively). At that point, as the haematological parameters were normal, we decided empirically to restart treatment at a maintenance dose of $3 \mu \mathrm{g} / \mathrm{kg} /$ day twice a week to avoid relapse. Five months later, with no evidence of clinical deterioration or haematological response, treatment was stopped and after a further 18 months the patient remains symptom free.

The successful remission of our patient, the seven published cases of GM-CSF in the treatment of $\mathrm{PAP}_{1}^{1-3}$ and the low incidence of side effects compared with the whole lung lavage technique prompt us to recommend GM-CSF as a first line treatment option in these patients.

M G de Vega

Respiratory Department, Hospital Virgen de las $\mathrm{N}$ ieves, $\mathrm{G}$ ranada, Spain

A Sánchez-Palencia

Chest Surgery Department, Hospital Virgen de las $\mathrm{N}$ ieves

A Ramírez, S Cervera

Anesthesia Department, Hospital Virgen de las $\mathrm{N}$ ieves
J Aneiros

Pathology Department, Hospital Clinico Universitario, G ranada, Spain

Correspondence to: Dr A Romero, Respiratory Department, Hospital Virgen de las N ieves, A vda de la Constitucion, Granada, Spain; aromeroor@nexo.es

\section{References}

1 Seymour JF, Begley CG, Dirksen U, et al. Attenuated hematopoietic response to granulocyte-macrophage colony stimulating factor in patients with acquired pulmonary alveolar proteinosis. Blood 1998;92:2657-67.

2 Scoch OD, N ierhoff N, Dubach HU, et al. Trea tment of pulmonary alveolar proteinosis (PAP): is G M-CSF an option? Eur Respir J 1998;12:131s.

3 Barraclough RM, Gillies AJ. Pulmonary alveolar proteinosis: a complete response to G M -CSF therapy. Thorax 2001;56:664-5.

\section{Conventional RIA} underestimates cortisol suppression in the presence of prednisolone

The recent letter from $\mathrm{M}$ eijer et $\mathrm{al}^{1}$ concludes that measuring serum cortisol by RIA severely underestimates serum cortisol suppression in the presence of oral prednisolone. This is rather a sweeping statement as the underestimation will, of course, depend on the degree of the cross reactivity with the particular assay. For example, in another study where inhaled fluticasone and oral prednisolone were compared in asthmatic patients and the cross reactivity of the RIA was quoted at $11 \%$, it was found that $1 \mu \mathrm{g}$ inhaled fluticasone (pM DI plus spacer) was equivalent to $8.5 \mathrm{mg}$ (95\% Cl 5.7 to 11.2 ) oral prednisolone for suppression of 08.00 hour plasma cortisol.

From the data from Meijer et al for HPLC morning serum cortisol levels, prednisolone $30 \mathrm{mg}$ per day produced $72 \%$ suppression compared with $38 \%$ suppression for fluticasone $2 \mathrm{mg}$ per day (by DPI). Extrapolating between these two values, it seems that $1 \mathrm{mg}$ per day inhaled fluticasone produces equivalent serum cortisol suppression to $7.9 \mathrm{mg}$ per day oral prednisolone. This is similar to our own estimated ratio of $8.5 \mu \mathrm{g}: 1$ using RIA. Furthermore, in another dose ranging study by Casale et $\mathrm{al}^{3}$ in asthmatics which compared the effects of inhaled fluticasone and prednisone on 22.00 hour serum cortisol levels (area under the curve) using HPLC, the relative degree of suppression was $15 \%$ for fluticasone MDI $440 \mu \mathrm{g}$ daily compared with $55 \%$ for prednisone $7.5 \mathrm{mg}$ daily, which extrapolates to $1 \mathrm{mg}$ fluticasone MDI being systemically equivalent to $4.6 \mathrm{mg}$ prednisone for adrenal suppression. As the addition of a large volume spacer doubles the adrenal suppression with fluticasone via $\mathrm{MDI},{ }^{4}$ the ratio reported by Casale et al in asthmatic patients equates to $1 \mathrm{mg}$ fluticasone via MDI plus spacer producing equivalent suppression to $9.2 \mathrm{mg}$ prednisone, which is similar to our own ratio of $8.5 \mu \mathrm{g}: 1$. $^{2}$

Taking all these data together clearly suggests that inhaled fluticasone is highly systemically bioavailable and produces systemic adverse effects at high doses which are equivalent to those produced by low doses of oral prednisolone.

BJ Lipworth

Professor of Allergy and Pulmonology, Asthma \& Allergy Research $\mathrm{G}$ roup, Department of Clinical Pharmacology and Therapeutics, N inewells Hospital and M edical School, University of Dundee, Dundee DD1 9SY, UK; b.j.lipworth@dundee.ac.uk

References

1 Meijer RJ, Postma DS, Kerstjens HAM Conventional RIA underestimates cortisol suppression in the presence of prednisolone. Thorax 2002; 57:374

2 Wilson AM, Lipworth B]. Short-term dose-response relationships for the relative systemic effects of oral prednisolone and inhaled fluticasone in asthmatic adults. $\mathrm{Br} J$ Clin Pharmacol 1999;48:579-85.

3 Casale TB, N elson HS, Stricker W E, Raff H, et al. Sup pression of

hypothalamic-pituitary-adrenal axis activity with inhaled flunisolide and fluticasone propionate in adult asthma patients. Ann Allergy A sthma Immunol 2001;87:379-85.

4 Dempsey OJ, W ilson AM, Coutie W J, et al. Evaluation of the effect of a large volume spacer on the systemic bioactivity of fluticasone propionate metered-dose inhaler. Chest 1999;116:935-40

\section{Authors' reply}

We thank Dr Lipworth for his comments. The ratio of systemic effects of fluticasone to prednisolone cannot be deduced reliably from our data, but we agree that the suppression we found is probably not markedly different from the one found by his group or from that of others in the literature.

However, this was not the content of-or the reason for-our note in Thorax. Our attention was drawn at a rather late stage to the fact that assessing prednisolone induced cortisol suppression by conventional radioimmunoassay (RIA) could lead to underestimation of suppression due to cross reactivity in the assay. ${ }^{12}$ We therefore subsequently compared cortisol results measured by conventional RIA with values measured by HPLC and, indeed, a significant underestimation in the presence of prednisolone was detected. Other researchers and clinicians might not be aware of this problem when assessing cortisol suppression by systemic corticosteroids.

R J Meijer, H A M Kerstiens

Department of Pulmonary M edicine, University Hospital G roningen, Hanzeplein 1, Postbox 30.001, N L-9700-RB G roningen, The N etherlands: h.a.m.kerstjens@int.azg.nl

\section{References}

1 Honour JW. Fluticasone in asthma. Thorax 2000;55:724.

2 Meijer RJ, Kerstiens HAM, A rends LR, et al. Effects of inhaled fluticasone and oral prednisolone on clinical and inflammatory parameters in patients with asthma. Thorax $1999 ; 54: 894-9$.

Inhaled corticosteroid dosage in asthma

We would like to congratulate Ward and colleagues $^{1}$ on their very important study which showed that significant changes in airway basement membrane thickness in asthma were not observed until after 3 
months of treatment with high dose inhaled corticosteroids (ICS), by which time maximum improvement in lung function and airway inflammation had already occurred.

The authors remind us that current guidelines advocate titration of ICS dosages against symptoms and spirometric data, and express their concern that, under these guidelines, ICS treatment would have been stepped down at 3 months, before the maximal benefit in airway hyperresponsiveness (AHR) and airway remodelling had been achieved. However, we have shown in a long term study of inhaled budesonide ${ }^{2}$ that AHR continued to improve over an 18 month period even while the ICS dose was being down-titrated. In this study AHR improved by a mean of 3.1 doubling doses after 4 months of high dose budesonide treatment, with a further 1.6 doubling dose improvement over 14 months of ICS dose reduction.

Ward and colleagues used high dose ICS (equivalent to $3000 \mu \mathrm{g} /$ day beclomethasone), and commented that the changes they observed may well have been achieved with much lower doses. However, in the 2 year study by Sont and colleagues which tested the addition of AHR to the usual treatment algorithm, ${ }^{3}$ patients receiving approximately $300 \mu \mathrm{g} /$ day ICS did not show the reductions in basement membrane thickness and exacerbations which were seen in the intervention group. The latter group started with approximately $1100 \mu \mathrm{g} /$ day, reducing to $700 \mu \mathrm{g} /$ day. In our double blind study ${ }^{2}$ patients who commenced treatment with budesonide $1600 \mu \mathrm{g} /$ day ultimately achieved the same improvement in AHR as those starting with $3200 \mu \mathrm{g} /$ day. However, the higher starting dose resulted in more rapid normalisation of airway responsiveness and a significantly reduced rate of exacerbations in patients who achieved normal airway responsiveness.

Further studies are needed to establish the optimal dosing regimen required for long term achievement of optimal asthma control and reversal of remodelling. It appears that initial ICS doses may need to be somewhat higher than those required to achieve clinical improvement alone, but the dosage may be able to be down-titrated without loss of benefit. As Ward and colleagues have shown short term studies will primarily reflect anti-inflammatory effects, but it is important that guidelines concerning ICS dosages should also take into account long term studies which reflect changes in remodelling.

H K Reddel, G B Marks, C M Salome, C R Jenkins

Institute of Respiratory Medicine, Camperdown, N SW 2050, Australia; hkr@mail.med.usyd.edu.au
References

1 Ward C, Pais M, Bish R, et al. Airway inflammation, basement membrane thickening and bronchial hyperresponsiveness in asthma. Thorax 2002:57:309-16.

2 Reddel HK, Jenkins CR, M arks G B, et al. 0 ptimal asthma control, starting with high doses of inhaled budesonide. Eur Respir I $2000 ; 16: 226-35,579$ (erratum)

3 Sont JK, W illems LN A, Bel EH, et al and the AM PUL Study G roup. Clinical control and histopathologic outcome of asthma when using airway hyperresponsiveness as an additional guide to long-term treatment. $\mathrm{Am}$ ] Respir Crit Care Med 1999;159:1043-51.

\section{Authors' reply}

We would like to thank $\mathrm{Dr}$ Reddel and colleagues for their encouraging and constructive communication regarding our study. ${ }^{1}$ An implication of our findings was that titration of inhaled corticosteroid (ICS) medication "simply" against symptoms and basic spirometric values, as specified in current international guidelines, may be inadequate leading to reduction of ICS before optima benefit in terms of airway remodelling and bronchial hyperreactivity (BHR). ${ }^{1}$ We feel that our data are complementary to those of Sont et $\mathrm{al}^{2}$ who found that modulation of ICS against BHR led to fewer exacerbations, greater improvement in forced expiratory volume in 1 second $\left(\mathrm{FEV}_{1}\right)$ and, in a subgroup who agreed to participate, a significant reduction in reticular basement membrane thickening compared with a group treated using current guidelines

Understandably, but unfortunately, the 2 year study by Sont et al was restricted to two biopsy episodes and inflammatory and remodelling changes could have occurred at any time during the 2 years between bronchoscopies. It was of interest that patients in the two treatment groups were not different in terms of inflammatory cell changes. Overall, the scarce pathophysiological data that are available indicate that long term modulation of at least a component of BHR might involve changes in airway remodelling, ${ }^{12}$ with earlier changes in BHR being more related to cellular inflammation.

Our experience is that adequately powered bronchoscopic studies ${ }^{3}$ are particularly de manding, and we do not advocate routine direct assessment of airway remodelling. ${ }^{1}$ The use of BHR testing, or other physiological measurements that may reflect airway remodelling, ${ }^{4}$ is perhaps more practicable in contributing to the assessment of asthma control. However, in a survey of the British Thoracic Society Directory of Laboratories, the majority of the $68 \%$ of centres that responded did not perform BHR assessment, and the median number of tests per year in the 58 of the 139 responders that did was 25 (range 1-480). ${ }^{4}$ In addition, even when standardised methodology is adopted for academic multicentre studies, there is considerable variability even when using "identical" BHR equipment.

Asthma guidelines have to be firmly placed in the real world and it is incumbent on clinical researchers to respond to this, as well as concerns regarding potential for overtreatment. ${ }^{6}$ Further work is required and, in particular, we agree with Reddel and colleagues that further studies are needed to establish the optimal dosing regimen required for long term achievement of optimal asthma control and reversal of remodelling. ${ }^{7}$ The results of such work may have future significance for the refinement of evidence based guidelines relating to the initiation and duration of asthma treatments.

C Ward, D Reid, E H Walters

Sir W illiam Leech Centre, University of $\mathrm{N}$ ewcastle upon Tyne, and Clinical Sciences, University of Tasmania, A ustralia chris.ward@med.monash.edu.au

\section{References}

1 Ward C, Pais M, Bish R, et al. Airway inflammation, basement membrane thickening and bronchial hyperresponsiveness in asthma. Thorax 2002;57:309-16

2 Sont JK, W illems LN A, Bel EH. Clinical control and histopathologic outcome of asthama when using airway responsiveness as an additional guide to long term treatment. Am J Respir Crit Care M ed 1999;159:1043-51.

3 Ward C, David P, Johns, et al. Reduced airway distensibility, fixed airflow limitation and airway wall remodelling in asthma. Am J Respir Crit Care Med 2001;164:1718-21.

4 Butterfield AK, Cushley MJ. Bronchial provocation testing with histamine and methacholine: current UK practice. Thorax 2001;56(Suppl III):iii66, abstract P68 (cited in Richardson CM, Medford AR, G reen RH. British Thoracic Society W inter M eeting 2001 Thorax 2002;57:286-8)

5 Ward RJ, W ard C, Johns DP, et al. European Community Respiratory Health Survey calibration project of dosimeter driving pressures. Eur Respir J 2002;19:252-6.

6 Wong CA, W alsh LI, Smith CJ, et al. Inhaled corticosteroid use and bone-mineral density in patients with asthma. Lancet 2000;355:1399-403.

7 Reddel HK, Jenkins CR, M arks G B, et al. 0 ptimal asthma control, starting with high doses of inhaled budesonide. Eur Respir $2000 ; 16: 226-35$. 
LETTERS TO THE EDITOR

If you have a burning desire to respond to a paper published in Thorax, why not make use of our "rapid response" option? Log on to our website (www.thoraxjnl.com), find thle paper that interests you, and send your response via email by clicking on the "eletters" option in the box at the top right hand corner.

Providing it isn't libellous or obscene, it will be posted within seven days. You can retrieve it by clicking on "read eletters" on our homepage.

The editors will decide as before whether to also publish it in a future paper issue.

\section{NIV guidelines}

We congratulate the British Thoracic Society (BTS) Standards of Care Committee on their excellent guidelines on non-invasive ventilation (NIV) in acute respiratory failure. ${ }^{1}$ The guidelines are timely in that many district general hospitals (DGH) are setting up an NIV service. If our DGH experience is typical others may be surprised how quickly NIV takes off. Our DGH serves a catchment area of about 200000 people and use of NIV has increased from 51 patients in the year 1998/9 to 227 in $2000 / 1$. Whereas in $1998 / 978 \%$ of all the NIV treated patients were on the intensive care unit (ICU), in 2000/1 71\% were treated on wards. The keen involvement of the ICU anaesthetists has been pivotal in setting up the service.

We would query the statement that all patients started on NIV should be transferred to the care of a respiratory physician as soon as possible. In 2000/l 65 patients were treated on the ICU with NIV, many of these surgical patients being weaned off ventilators. Similarly, 28 "surgical" patients were treated on the wards with NIV. Should chest physicians really have to take over hospital care of all these patients?

The guidelines do not address the issue of the use of NIV in palliation of breathlessness. In acute exacerbations of chronic obstructive pulmonary disease (COPD) breathlessness settles more rapidly with NIV than with conventional treatment. ${ }^{2}$ In patients with severe respiratory distress who refused endotracheal intubation, anecdotally NIV was effective in reducing breathlessness. ${ }^{3}$ It is not surprising that the role of NIV in treating breathlessness is unclear, given the uncertainty over the efficacy of other interventions which have been available for many years such as oxygen, benzodiazepines, morphine, or breathing exercises. We have found NIV useful in reducing dyspnoea in some patients with end stage respiratory disease, and agree with the guidelines that it is vital it be clearly documented whether NIV is being used with palliative or curative intent, and whether or not to proceed to invasive ventilation.

\section{D Shee, M Green} Queen Mary's Hospital, Sidcup, Kent DA14 6LT, UK

\section{References}

1 British Thoracic Society Standards of Care Committee. Non-invasive ventilation in acute respiratory failure. Thorax 2002;57:192211.

2 Plant PK, Owen JL, Elliott MW. Early use of non-invasive ventilation for acute exacerbations of chronic obstructive pulmonary disease on general respiratory wards: a multi-centre randomised controlled trial. Lancet 2000:355: 1931-5.

3 Meduri GU, Fox RC, Abou-Shala N, et al. Non-invasive mechanical ventilation via face mask in patients with acute respiratory failure who refused endotracheal intubation. Crit Care Med 1994;22:1584-90.

We read the BTS guideline on non-invasive ventilation (NIV) in acute respiratory failure with great interest. The paper is an excellent summary and a very good reference for a number of situations related to this nove approach. We have, however, some questions which we wish to raise.

Nowadays it is widely accepted that NIV is superior to both invasive mechanical ventilation and standard medical treatment in selected patients with exacerbations of hypercapnic chronic obstructive pulmonary disease (COPD). The skills required for NIV are easily learnt and the equipment required is relatively inexpensive. The complication rate is very low compared with invasive ventilation, and it has been shown by Plant et $a^{2}$ that NIV is cheaper with a lower mortality rate than standard medical treatment in patients with COPD. The use of NIV outside the ICU and by physicians, nurses, or respiratory care practitioners is also beneficial, allowing early intervention to prevent further respiratory deterioration, access to respiratory support for patients who would not otherwise be admitted to the ICU, and the provision of support in a less intimidating setting. Success rates of NIV in such patients can be higher than $90 \%,{ }^{3}$ depending on appropriate selection of patients, close monitoring in the first 4-6 hours, and the experience of the staff. However, according to the BTS guideline, ${ }^{1}$ NIV does not appear to be a suitable treatment modality for low income countries because of the limited availability of ICU facilities. Although there is no doubt that the best settings in which to use NIV are those stated in the guideline, it is not always possible for a low income country to set up a countrywide ICU service. The number of patients with acute COPD exacerbations is no lower than in developed countries, so shouldn't we use NIV in selected COPD patients with acute exacerbations even if there is no ICU service in the near area? Would it be ethical not to use this simple and inexpensive device in those selected patients if you have a well trained staff but no ICU service?

O Dikensoy, A Filiz, E Ekinci

Department of Pulmonary Diseases, Gaziantep University, School of Medicine, Gaziantep 27070 Turkey; dikensoy@yahoo.com

\section{References}

1 British Thoracic Society Standards of Care Committee. Non-invasive ventilation in acute respiratory failure. Thorax 2002;57:192211

2 Plant PK, Owen JL, Elliott MW. Early use of non-invasive ventilation for acute exacerbations of chronic obstructive pulmonary disease on general respiratory wards: a multicentre randomised controlled trial. Lancet 2000;355:1931-5.

3 Kramer N, Meyer TJ, Meharg J, et al. Randomized prospective trial of noninvasive positive pressure ventilation in acute respiratory failure. Am J Respir Crit Care Med 1995;151:1799-806.

\section{Author's reply}

In response to the criticism that it is unnecessary to transfer all patients on non-invasive ventilation (NIV) to the care of a respiratory physician as soon as possible, these are guidelines not rules. I am unhappy with the suggestion that NIV should be managed by surgeons, although clearly there may be hospitals where the surgeons have sufficient training and experience in NIV for this to be acceptable. I agree that NIV can be used to palliate breathlessness, but I did not specifically address this area of use in the guideline.

In answer to the question as to whether it would be ethical to use NIV if there is no intensive care service available, I agree that in special circumstances this would be entirely reasonable.

W J M Kinnear

Department of Respiratory Medicine, Queen's Medical Centre, Nottingham NG7 2UH, UK; William.Kinnear@mail.qmcuh-tr.trent.nhs.uk

\section{CORRECTION}

\section{GM-CSF therapy in pulmonary alveolar proteinosis}

In the letter by $M$ G de Vega et al entitled "GM-CSF therapy in pulmonary alveolar proteinosis" which appeared on page 837 of the September issue of Thorax (Volume 57, No 9), the name of Dr A Romero was inadvertently omitted as the first author. The authors of the letter should have been: A Romero, M G de Vega, A Sánchez-Palencia, A Ramírez and $S$ Cervera. The publishers apologise for this error. 